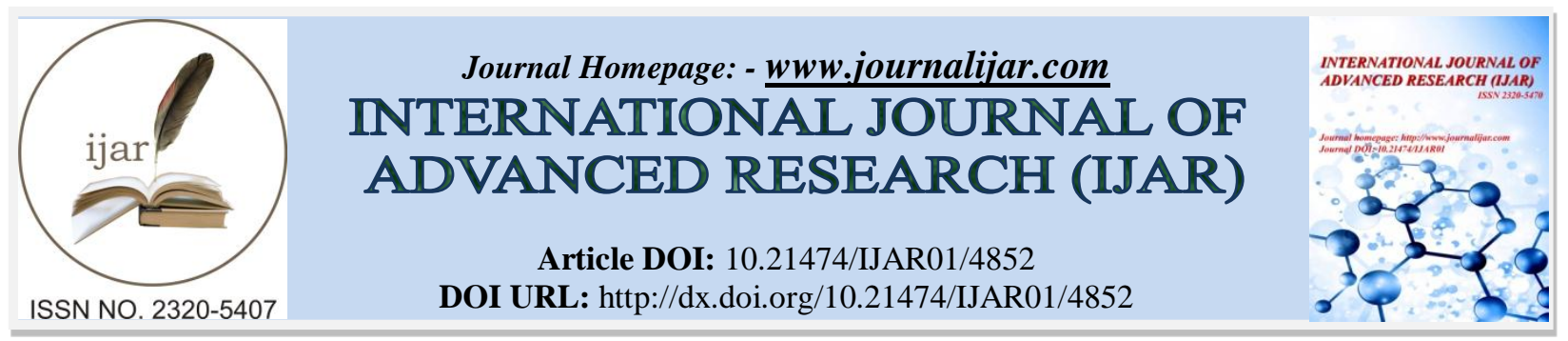

RESEARCH ARTICLE

\title{
COMPARATIVE QUALITY EVALUATION OF DIFFERENT OLMESARTAN MEDOXOMIL GENERIC TABLETS MARKETED IN BANGLADESH.
}

Tasnova Tasnim* and Md. Monirul Hasan.

Faculty of Medicine, Department of Pharmacy, University of Asia Pacific, 74/A Green Road, Dhaka-1215, Bangladesh.

\section{Manuscript Info}

........................

\section{Manuscript History}

Received: 15 May 2017

Final Accepted: 17 June 2017

Published: July 2017

Key words:-

Olmesartan medoxomil, dissolution, difference factor $\left(\mathrm{f}_{1}\right)$, similarity factor $\left(f_{2}\right)$.

\section{Abstract}

The objective of the present study was to evaluate and compare between nine different brands of Olmesartan medoxomil 40mg which are commercially available in Bangladeshi market. We chose nine popular brands, coded them from $\mathrm{O} 1$ to $\mathrm{O} 9$ and purchased them from local private pharmacies .The physicochemical equivalence of nine brands were determined through the evaluation of both official and non-official standards according to the USP pharmacopoeia including uniformity of weight, thickness, diameter, friability, hardness, disintegration, dissolution rate and drug content. All the tested brands conformed to the official tests for weight variation, friability, disintegration and dissolution tests. The friability test was within the specified limit (except for Brand O2). All formulations disintegrated within 15-30min. The percentage content of active ingredient of almost all brands of Olmesartan medoxomil tablets showed values within the monograph specifications (95-105\%). The dissolution profiles showed inter and intra brand variability but all samples attained $75 \%$ dissolution within $45 \mathrm{mins}$ and complied with USP monograph. The nine brands evaluated in this study could be considered biopharmaceutically and chemically equivalent and it had been determined calculating difference factor and similarity factors. Moreover, the result of all these parameters of different brands were in the pharmacopoeia limits. So it could be concluded that marketed pharmaceutical tablets of Olmesartan medoxomil of these brands are safe, effective and efficacious as well as satisfy quality control limits of pharmacopoeia.. Therefore, patients can safely shift from one brand to another.

Copy Right, IJAR, 2017,. All rights reserved.

\section{Introduction:-}

Since past decade, there has been an augmented demand for more patient-friendly and compliant dosage forms, the demand for developing new technologies have been increased with the same (Shyamala and Narmada, 2002). To fulfill these remedial needs, pharmaceutical technologists have developed a novel oral dosage form known as Tablets which disintegrate rapidly in stomach, usually in a minute. Drug dissolution and absorption as well as onset of action and bioavailability is appreciably greater in tablets than those observed from other conventional dosage forms (Sreenivas et al., 2005; Seager, 1998; Bradoo et al., 2001). Now-a-days for the treatment of maximum 
illnesses oral route represents the favored way of administration, to produce rapid systemic effects, owing to its quite a few advantages and high patient compliance compared to other routes (Valleri et al., 2004)

The objective of designing and manufacturing of compressed tablet is to administer orally the correct amount of drug in the proper form, at the proper time, in the intended location, and to have its chemical integrity protected till that point. In course of time oral route of drug administration has been widely acceptable and solid dosage forms administered orally represent the most preferred class of products (Gilbert et al., 2011). Tableting behavior, hence depends on some in vitro characteristics of the tablets, affected by the choice of crystal form (Gilbert et al., 2011) or the degree of crystallinity (Rasenack and Muller, 2002). Amorphous particles are likely to show plastic deformation upon compaction, substantial lubricant sensitivity and stronger bonding than those in the crystalline form (Hansen et al., 2004), resulting in higher mechanical strength (Bozic et al., 2008). Despite the importance of such information, in the case of Olmesartan medoxomil, it is only known that its crystallinity is highly on account of its poor compactness. However, there is no data on how these properties are related to each other, up to now (Alderborn and Nystrom, 1996).

Olmesartan medoxomil is an angiotensin II receptor antagonist treating hypertension which is a major public health problem globally in both the developed and developing countries. In Bangladesh, according to Non Communicable Disease risk factors survey, approximately $20 \%$ of adult and $40-65 \%$ of elderly people suffer from hypertension. Many risk factors underlying hypertension have been identified including non- modifiable factors such as age, gender, genetic factors, and race, as well as modifiable factors including overweight, high sodium intake, and reduced physical activity (Koly et al., 2010). Olmesartan medoxomil is a pro-drug containing an ester moiety that, after oral administration, is rapidly cleaved to release the active form olmesartan. Blockade of the angiotensin II receptor inhibits the negative regulatory feedback of angiotensin II on renin secretion, but the resulting increased plasma renin activity and circulating angiotensin II levels do not overcome the effect of olmesartan on blood pressure (Giles et al., 2007). Oral olmesartan medoxomil 10-40 $\mathrm{mg}$ once daily is recommended for the treatment of adult patients with hypertension (Scott and McCormack, 2008).

Olmesartan being a potential agent of choice in treating hypertension hinted us to select this drug to investigate upon. The purpose of the study was to make a comparison of in vitro quality control parameters, differentiate between the aesthetics and identify dissimilarities in physicochemical properties between different marketed Olmesartan medoxomil tablets in Bangladesh.

\section{Material and Method:- Collection of sample:-}

The API for Olmesartan medoxomil has been collected from Incepta Pharmaceuticals Ltd. in January, 2017 following ethical procedure. The marketed sample of nine (9) brands of Olmesartan medoxomil $40 \mathrm{mg}$ tablet were purchased at M.R.P from different Retail pharmacy from Dhaka, Bangladesh. These tablets of nine brands were coded as $\mathrm{O} 1$ to $\mathrm{O} 9$. The samples were properly checked for their physical appearance, name of manufacturer, batch number, and manufacturing date, expiry date, manufacturing license number, D.A.R. number \& maximum retail price at the time of purchase. None of samples were bought $\&$ analyzed which exceed the expiry date and both of these samples were stored under appropriate condition. The label information of nine different brands of Olmesartan medoxomil tablets are shown in (Table 1).

\section{Inspection of diameter and thickness:-}

Twenty tablets from each brand were selected for diameter and thickness tests. Diameter and thickness were determined by using digital slide caliper. Mean thickness, diameter and their standard deviations (SD) were calculated. Shape was determined by comparing the shape of the tablet with FDA approval standards for tablets shape.

\section{Hardness test:-}

Crushing strength $(\mathrm{N})$ was determined with an automatic hardness tester (VEEGO, INDIA). Twenty tablets were randomly selected from each brand and the pressure required to crush each were recorded.

\section{Friability test:-}

Twenty tablets from each brand were weighed and subjected to rotation by employing a VEEGO friabilator (VFT-2, India) which was operated at 25 RPM for 4 minutes. All tablets were weighed before and after 100 revolutions. 


\section{Weight variation test:-}

For weight variation twenty tablets from each brand were weighed individually using an analytical balance (TE214S, Sartorious Germany). Variation in weight of each individual tablets, represented as the Standard Deviation were calculated using Microsoft Excel 2013.

\section{Standard curve preparation:-}

Construction of a standard concentration curve of a solution is done by measuring the absorbance of several different known concentrations of the solution prepared from the pure active substance and graphing the results by plotting absorbance on the $\mathrm{Y}$-axis and concentration on the $\mathrm{X}$-axis. Spectrophotometry can be used to measure the absolute or relative concentration of a characterized substance in solution. Through this we can get a $y=m x+c$ (Straight line) equation.

Here $10 \mathrm{mg}$ of standard API of Olmesartan medoxomil was weighed with electronic balance and taken in a $100 \mathrm{ml}$ volumetric flask then buffer solution was added to volumetric flask upto $100 \mathrm{ml}$ to make solution of $100 \mathrm{mcg} / \mathrm{ml}$. Then again $10 \mathrm{ml}$ from this solution was again taken into a $100 \mathrm{ml}$ volumetric flask and was diluted up to $100 \mathrm{ml}$ to make solution of $10 \mathrm{mcg} / \mathrm{ml}$. This stock solution has been used to prepare samples of varied concentrations with absorbance in proximity to or less than 1 measured by UV spectrophotometer at $255 \mathrm{~nm}$ against blank. Then absorbance was plotted against the concentration to obtain the standard curve using Microsoft Excel 2013.

\section{Determination of potency:-}

Four tablets were taken and crushed thoroughly in mortar pastel. Amount of powdered tablet containing 10mg of Olmesartan medoxomil was then dissolved in $100 \mathrm{ml}$ buffer media. Solution was filtered and $10 \mathrm{ml}$ filtrate was taken in a test tube and was diluted with $100 \mathrm{ml}$ of buffer solution. Absorbance was measured in a spectrophotometer at $255 \mathrm{~nm}$ wavelength. Potency of the tablet was than determined concentration obtained from absorbance and dilution factor. According to USP-32 specification of potency for tablet should be (100 \pm 5$) \%$

\section{Disintegration:-}

It is the required time that is given under condition of tablets to disintegrate into particles. It depends on the hardness of the tablets and use of binders during granulation etc. If too much binder is used a tablet does not break down into particles. Thus the tablet does not disintegrate at required time.

\section{In vitro dissolution test:-}

Dissolution test of the tablets were performed using USP dissolution apparatus II (paddle) (VEEGO, India) in 1000 $\mathrm{ml}$ phosphate buffer as dissolution media, at $50 \mathrm{rpm}$ and $37 \pm 0.5^{\circ} \mathrm{C}$ temperature. Test sample (10ml) was withdrawn at particular time (at 5, 15, 30, 45, and 60 minutes) interval and replaced with fresh buffer solution of same volume and maintained at the same temperature. Collected sample were filtered and analyzed after suitable dilution by UV- Spectrophotometer at $255 \mathrm{~nm}$ against phosphate buffer as blank according to British Pharmacopeia, 2013 (BP, 2013). To determine the concentration of sample, help from the standard curve of pure API was taken.

\section{Results and Discussion:-}

\section{Price fluctuation:-}

Price, manufacturing and expiry date of Olmesartan medoxomil tablets were observed in the drug outlets on single visit during medicine collections. The highest price was for brand O5 (15.50 taka per tablet) and minimum for brand O3 (13.70 taka per tablet) while there was no major variation in the physical appearance of the tablets (Graph 1).

\section{Diameter and thickness test:-}

As the weight of a compressed tablet is dependent on density, diameter, and thickness, determination of the diameter and thickness of the tablets at regular intervals during the production may prevent potential problems related to tablet weight and content uniformity at an early stage (Akgeyik et al., 2016). Among nine brands, brand $\mathrm{O} 4$ had the highest average diameter $(13.35 \mathrm{~mm})$ whereas brand $\mathrm{O} 8 \mathrm{had}$ the lowest average diameter $(7 \mathrm{~mm})$. The average thickness was found to be between the ranges of (3.2-5.27) $\mathrm{mm}$ (Table 2).

\section{Hardness test:-}

The hardness of the tablet depends on the materials used, amount of binder, space between the upper and lower punches at the time of compression and pressure applied during the process of compression (Banker and Anderson, 
2011). Measuring the hardness of a tablet is not a reliable indicator for tablet strength as some formulations when compressed into very hard tablets tend to cap or lose their crown portions on attrition (Du and Hoag, 2003; Pisek et al., 2002). Hardness is referred to as a non-compendial test. Tablet hardness was found between 43.7-143.6 N. A force of about $40 \mathrm{~N}$ is the minimum requirement for a satisfactory tablet (Allen et al., 2011). Hence the tablets of all the selected brands were satisfactory for hardness and therefore, the batches can be considered as of good quality.

\section{Friability test:-}

Tablet hardness is not an absolute indicator of strength and therefore another measure of a tablet's strength, its friability, is often measured which is designed to evaluate the ability of the tablet to withstand abrasion in packaging, handling and shipping which can lead to capping, chipping, abrasion or even breakage of the tablets. Friability test is now included in the United States Pharmacopeia (USP, 1995) as a compendial test. The compendial specification for friability is $1 \%$. Usually harder the tablets less will be the percentage friability and vice versa. ${ }^{[21]}$ It was found that except for brand $\mathrm{O} 2$, the eight different brands of Olmesartan tablet were in accordance with the stated B.P/U.S.P guideline (Table 2).

\section{Test of uniformity of weight:-}

The weight variation test would be a satisfactory method of determining the drug content uniformity of tablets that is the uniformity of the drug distribution in the granulation or powder form which the tablets were made (Lachman et al., 1987). Brand $\mathrm{O} 1$ has average weight of $256 \mathrm{mg}$ and with a standard deviation of $\pm 4.00 \%$. All of the other 8 brands have average weight less than $500 \mathrm{mg}$. Among them, brand $\mathrm{O} 4$ weighed the highest (463.3 $\mathrm{mg}$ ) standing as the biggest tablet in the list (Table 2).

\section{Disintegration test:-}

Tablets are anticipated to break down into smaller particles or granules inside the stomach within a reasonable time to release the active ingredient into the body. This process will facilitate further dissolution in the biological fluids followed by gastrointestinal absorption, distribution, metabolism and excretion. It has to be pointed out that a product which fails to disintegrate will presumably fail dissolution criteria (Du and Hoag, 2003), thus the disintegration test serves as an element in the overall quality control of tablets manufacturing. According to BP specification, film coated tablets should disintegrate within $30 \mathrm{~min}$, while the USP specifies that both uncoated and film coated tablets should disintegrate within $30 \mathrm{~min}$. Here all brands of Olmesartan medoxomil were uncoated immediate release tablets and maximum time for disintegration was found $9.36 \mathrm{~min}$ for brand $\mathrm{O} 3$ (Table 2).

\section{Potency test:-}

Potencies of all the brands were found within 93.20-105.25\%. According to USP, if the dose of the drug is higher than the $60 \mathrm{mg}$ potency of the drug should be within 95-105\%. For highly potent, low-dose drugs this range is usually not less than $90 \%$ and not more than $110 \%$ of the labeled amount. Since the present study was conducted with large dose Olmesartan medoxomil tablets (40 mg), percent potency should be within 95\%-105\% (USP, 1995). All the brands, but brand O8, met this specification (Table 2).

\section{Dissolution test:-}

Intra-brand comparative assessment of percent drug release profile of all nine brands indicated increase in drug release after every 15 minutes although this increase altered from brand to brand. After 60 minutes, samples taken from brand $\mathrm{O} 1$ and $\mathrm{O} 9$ showed maximum drug release (104.20 and 104.93\% respectively) and brand O4 exhibited minimum drug release $(90.86 \%)$ among others. Since all the brands released more than $80 \%$ drug in the first 45 minutes, it can be assumed that all the brands possessed good dissolution profile although the brands were manufactured by different companies using different excipient in different proportion (Graph 2)

\section{Comparison of dissolution data:-}

Difference factor $\left(f_{1}\right)$, similarity factor $\left(f_{2}\right)$ and dissolution efficiency $(\% \mathrm{DE})$ were calculated to compare the dissolution profile. The following equations were used to calculate $\mathrm{f} 1$ and $\mathrm{f} 2$. Where $\mathrm{n}$ is the number of time points, $R_{t}$ is the dissolution value of reference product at time $t$ and $T_{t}$ is the dissolution value for the test product at time $t$. Similarity factor $\left(\mathrm{f}_{2}\right)$ has been adopted to compare dissolution profile by FDA and the European Agency for the Evaluation of Medicinal Products by the Committee for Proprietary Medicinal Products (CPMP). According to the FDA guidance (Waiver of in vivo bioavailability, 2000) dissolution profiles are similar if $\mathrm{f}_{1}$ values are between 0 and 15 and $\mathrm{f}_{2}$ values are between 50 and 100 . 


$$
\begin{aligned}
f_{1} & =\left\{\frac{\sum_{t=1}^{n}\left|R_{t}-T_{t}\right|}{\sum_{t=1}^{n} R_{1}}\right\} \times 100 \\
f_{2} & =50 \log \left\{\left(1+\frac{1}{n} \sum_{i=1}^{n}\left(R_{t}-T_{t}\right)^{2}\right)^{-0.5} \times 100\right\}
\end{aligned}
$$

Table 4 shows the $\mathrm{f}_{1}, \mathrm{f}_{2}$ values of the nine assigned brands in respect of brand $\mathrm{O} 1$ as a reference brand. Factors $\mathrm{f}_{1}$ and $\mathrm{f}_{2}$ were different and below the requirements in cases of similarity factors for products $\mathrm{O} 3, \mathrm{O} 4, \mathrm{O} 5, \mathrm{O} 7, \mathrm{O} 8$ and $\mathrm{O} 9$ when compared to brand O1. In cases of difference factors all were within the range except for brand O5 and O7. For brand $\mathrm{O} 2$ and $\mathrm{O} 6, \mathrm{f}_{1}$ was less than 15 and $\mathrm{f}_{2}$ value was more than 50 (Table 3). So brand $\mathrm{O} 2$ and $\mathrm{O} 6$ are similar with brand $\mathrm{O} 1$ and can be used interchangeably.

Table 1: Label information of different brands of Olmesartan medoxomil tablets (40 mg):

\begin{tabular}{|l|l|l|l|l|l|}
\hline Brand & Mfg. date & Exp. date & $\begin{array}{l}\text { Pack size } \\
\text { found (unit) }\end{array}$ & $\begin{array}{l}\text { Price per pack } \\
\text { (BDT) }\end{array}$ & $\begin{array}{l}\text { Price per unit } \\
\text { (BDT) }\end{array}$ \\
\hline O1 & February 2017 & February 2019 & 100 & 1500 & 15 \\
\hline O2 & October 2016 & October 2017 & 100 & 1500 & 15 \\
\hline O3 & April 2016 & April 2018 & 100 & 1370 & 13.70 \\
\hline O4 & August 2016 & August 2018 & 100 & 1400 & 14 \\
\hline O5 & January 2017 & January 2019 & 100 & 1550 & 15.50 \\
\hline O6 & July 2016 & July 2018 & 100 & 1500 & 15 \\
\hline O7 & April 2016 & April 2018 & 100 & 1475 & 14.75 \\
\hline O8 & May 2016 & May 2018 & 100 & 1450 & 14.50 \\
\hline O9 & September 2016 & September 2018 & 100 & 1500 & 15 \\
\hline
\end{tabular}

Table 2:- A summary of the quality control tests of Olmesartan medoxomil tablets:

\begin{tabular}{|l|l|l|l|l|l|l|l|}
\hline Brands & $\begin{array}{l}\text { Diameter } \\
(\mathbf{m m})\end{array}$ & $\begin{array}{l}\text { Thickness } \\
(\mathbf{m m})\end{array}$ & $\begin{array}{l}\text { Friability } \\
(\mathbf{\%})\end{array}$ & $\begin{array}{l}\text { Hardness } \\
(\mathbf{N})\end{array}$ & $\begin{array}{l}\text { Weight } \\
\text { Variation }(\mathbf{m g})\end{array}$ & DT (min) & $\begin{array}{l}\text { Potency } \\
(\boldsymbol{\%})\end{array}$ \\
\hline O1 & $9.61 \pm 0.07$ & $4.97 \pm 0.08$ & 0.08 & $64.4 \pm 0.99$ & $256 \pm 4.00$ & $2.07 \pm 0.86$ & 99.69 \\
\hline O2 & $9.27 \pm 0.06$ & $4.24 \pm 0.06$ & 1.2 & $59.8 \pm 0.76$ & $230 \pm 2.17$ & $4.41 \pm 0.88$ & 97.84 \\
\hline O3 & $9.61 \pm 0.04$ & $4.35 \pm 0.04$ & 0.47 & $74 \pm 0.87$ & $304 \pm 2.11$ & $9.36 \pm 0.65$ & 105.25 \\
\hline O4 & $13.35 \pm 0.08$ & $5.27 \pm 0.09$ & 0.07 & $143.6 \pm 1.68$ & $463.3 \pm 2.68$ & $2.33 \pm 1.12$ & 96.92 \\
\hline O5 & $10.13 \pm 0.04$ & $3.62 \pm 0.08$ & 0.15 & $61 \pm 0.58$ & $287 \pm 1.33$ & $3.72 \pm 0.78$ & 101.35 \\
\hline O6 & $12.045 \pm 0.07$ & $3.22 \pm 0.07$ & 0.28 & $94.6 \pm 0.80$ & $152.3 \pm 3.50$ & $2.23 \pm 0.91$ & 98.25 \\
\hline O7 & $7.2 \pm 0.06$ & $4.5 \pm 0.09$ & 0.1 & $65 \pm 2.6$ & $296.6 \pm 2.1$ & $4.40 \pm 1.0$ & 96.19 \\
\hline O8 & $7.0 \pm 0.07$ & $3.2 \pm 0.07$ & 0.3 & $58.7 \pm 0.6$ & $133.7 \pm 2.8$ & $1.25 \pm 0.81$ & 93.20 \\
\hline O9 & $7.3 \pm 0.08$ & $3.6 \pm 0.08$ & 0.2 & $43.7 \pm 2.9$ & $155.7 \pm 2.2$ & $6.18 \pm 0.65$ & 95.37 \\
\hline
\end{tabular}

*all values are presented as mean \pm standard deviation

Table 3:- $\mathrm{f}_{1}$ and $\mathrm{f}_{2}$ of nine brands of Olmesartan medoxomil tablets tested:

\begin{tabular}{|c|c|c|}
\hline Pair Comparison & Difference factor (f1) & Similarity factor (f2) \\
\hline O2 vs. O1 & 2.54 & 60.90 \\
\hline O3 vs. O1 & 13.45 & 46.17 \\
\hline O4 vs. O1 & 12.34 & 43.66 \\
\hline O5 vs. O1 & 16.25 & 48.91 \\
\hline O6 vs. O1 & 10.12 & 54.72 \\
\hline O7 vs. O1 & 17.18 & 40.87 \\
\hline O8 vs. O1 & 14.36 & 44.56 \\
\hline O9 vs. O1 & 9.14 & 42.98 \\
\hline
\end{tabular}




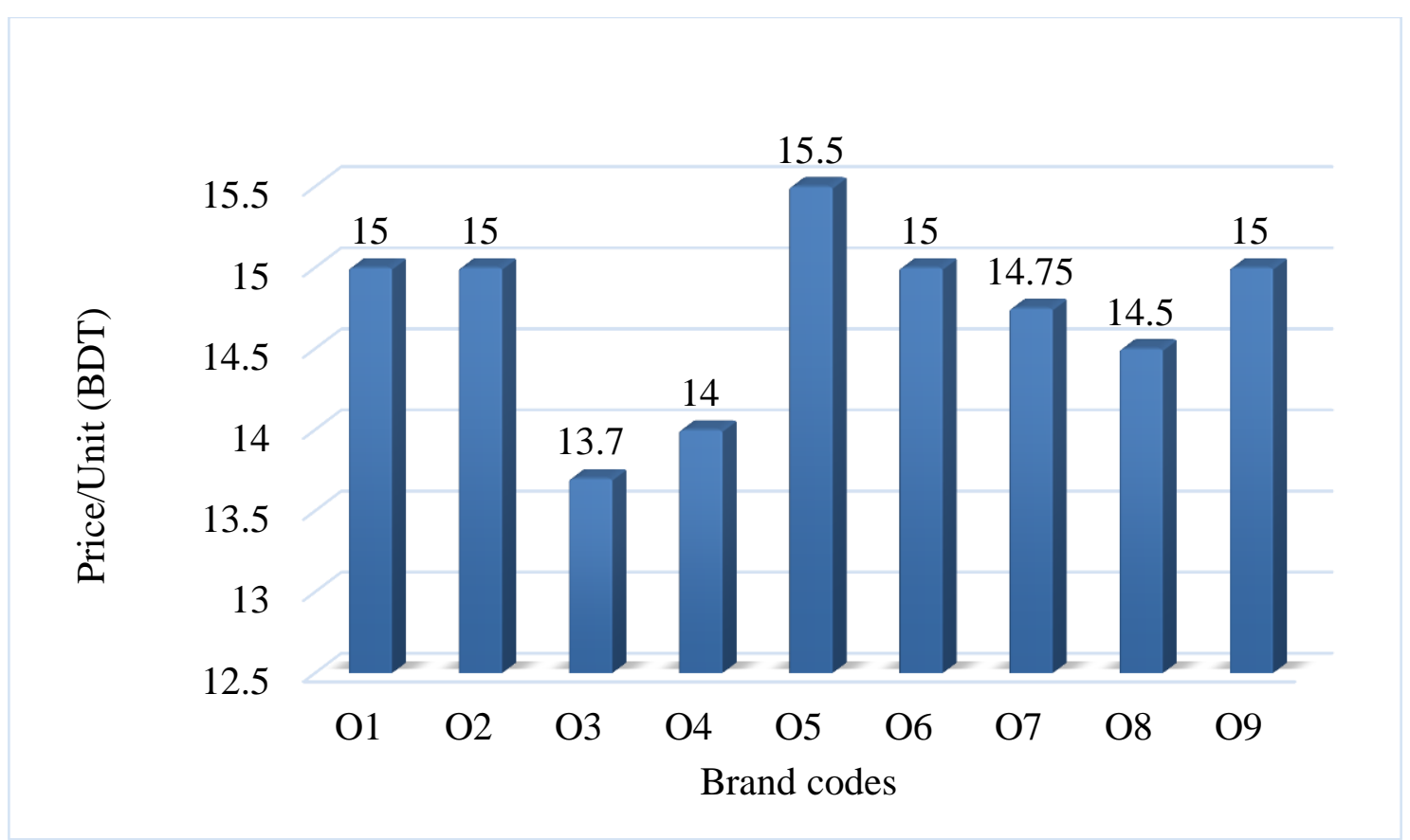

Graph 1:- Price fluctuation among the nine brands of Olmesartan medoxomil tablets

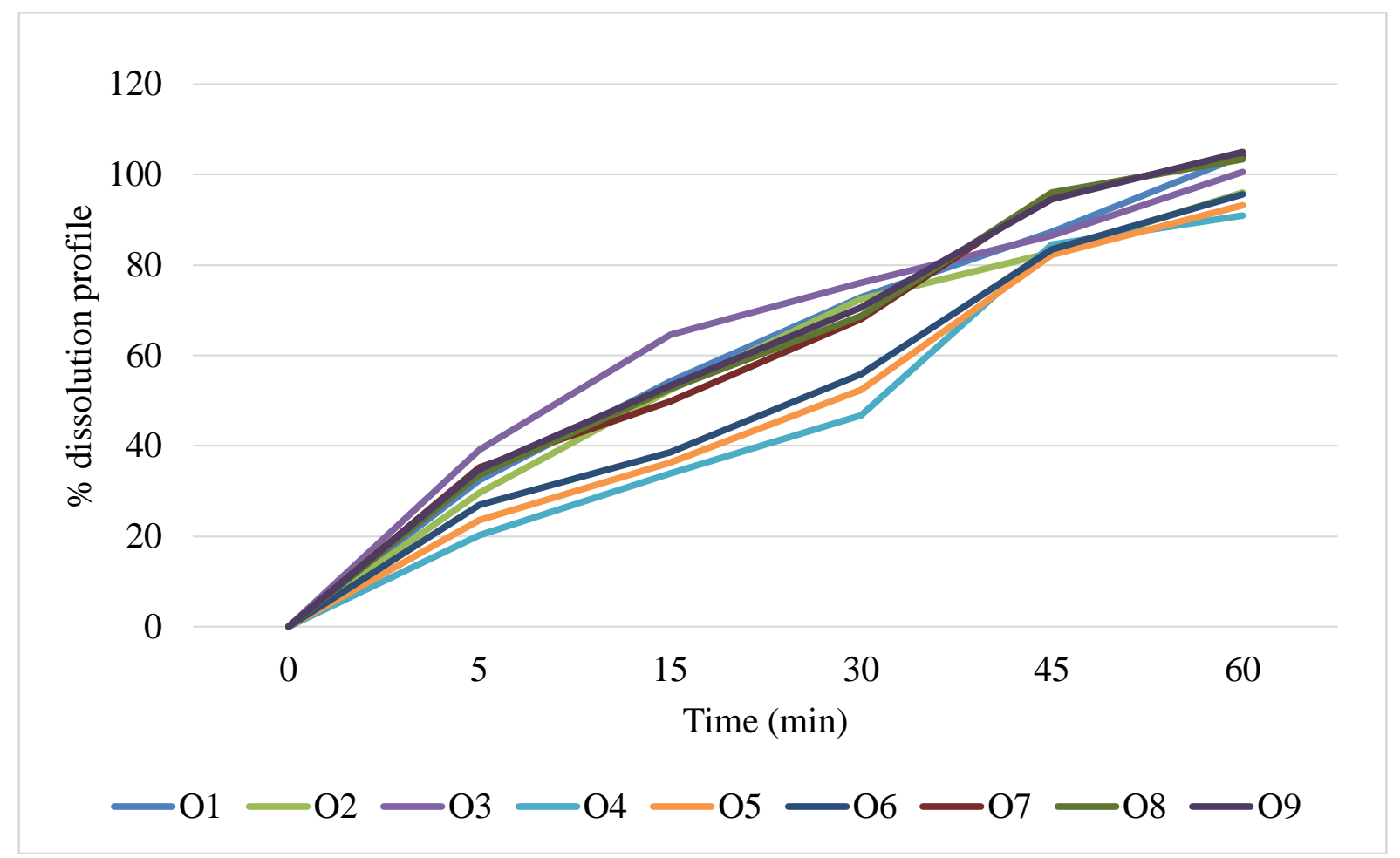

Graph 2:- Dissolution profile of nine brands of Olmesartan medoxomil tablets

\section{Conclusion:-}

Quality of a product refers to its complying with the standards preset to assure the desired purpose. It is a sensitive issue for a pharmaceutical product since these products are directly linked with the patient's life. A quality product gives not only better therapeutic efficacy but also gives consumer satisfaction and increases its market demand. So a pharmaceutical industry follows the international standards to ensure quality product and to give proper safety and efficacy. The present study was undertaken with an aim to evaluate Olmesartan medoxomil market 
preparations available in Bangladesh. After completing this study we can say that the pharmaceutical companies of Bangladesh are doing a great job by manufacturing good quality products in order to serve this country. The various in-vitro analysis results have helped us to come up with the conclusion that patients who are taking Olmesartan medoxomil can be sure of the drug being safe and effective as they match USP specifications and they can also safely switch from one brand to another. However, results for percentage potency and drug release were satisfactory but some in vivo tests are also recommended to strengthen the comments upon the marketed brands of Olmesartan medoxomil tablets.

\section{Acknowledgement:-}

Authors are obliged to the Pharmaceutical Technology Research Laboratory, University of Asia Pacific which has funded the research under the campus research and publication fund.

\section{Reference:-}

1. Shyamala, B., Narmada, G.Y. (2002): Rapid dissolving tablets: A novel dosage form. The Ind. Pharmacist, 13(8): 09-12.

2. Sreenivas, S.A., Dandagi, P.M., Gadad, A.P., Godbloe, A.M., Hiremath, S.P. (2005): Mastiholimath VS. Orodispersible tablets: New-fangled drug delivery systems - A review. Ind. J. Pharm. Educ. Res., 39(4): 177181.

3. Seager, H. (1998): Drug-delivery products and Zydis Fast-dissolving dosage form. J. Pharm. Pharmacol., 50: 375-382.

4. Bradoo, R., Shahani, S., Deewan, B., Sudarshan, S. (2001): Fast dissolving drug delivery system. J. Am. Med. Assoc. Ind., 4 (10): 27-31.

5. Valleri, M., Mura, P., Maestrelli, F., Cirri, M., Ballerini, R. (2004): Development and evaluation of glyburide fast dissolving tablets using solid dispersion technique. Drug Dev. Ind. Pharm., 30(5): 52534.

6. Gilbert, S.B., Neil, R.A. (2011): Tablets. In Lachman L, Lieberman HA, kanig JL, The theory and practice of industrial pharmacy 3rd edition. Editors: U.S.A, Lea \& Febigerverghese publishing House, pp 293-340.

7. Rasenack, N., Müller, B.W. (2002): Crystal habit and tableting behavior. International J. of Pharm., 244(12):45-57.

8. Hansen, T., Holm, P., Schultz, K. (2004): Process characteristics and compaction of spray- dried emulsions containing a drug dissolved in lipid. International Journal of Pharmacy, 287(1-2):55-66.

9. Bozic, D.Z., Dreu, R., Vrecer, F. (2008): Influence of dry granulation on compactibility and capping tendency of macrolide antibiotic formulation. International Journal of Pharmacy, 357: 44-54.

10. Alderborn, G., Nyström, C. (1996): Pharmaceutical powder compaction technology. New York: Marcel Dekker, 610.

11. Koly, K.N., Biswas, T., Islam, A. (2010): Increasing Prevalence of Hypertension in Bangladesh: A review.

12. Giles, T.D., Oparil, S., Silfani, T.N., Wang, A., Walker, J.F. (2007): Comparison of increasing doses of olmesartan medoxomil, losartan potassium, and valsartan in patients with essential hypertension. J. Clin Hypertens (Greenwich), 9:187-195.

13. Scott, L.J., McCormack, P.L. (2008): Olmesartan Medoxomil. Drugs, 68(9):1239-72.

14. British Pharmacopeia (BP), Her Majesty’s Stationary Office, London, 2013.

15. Akgeyik, E., Kaynak, M.S., Çelebier, M., Altınöz, S., Şahin, S. (2016): Evaluation of pharmaceutical quality of conventional dosage forms containing paracetamol and caffeine available in the Turkish drug market. J. Dissolution Technology, 23(2):36-41.

16. Banker, G.S., Anderson, N.R. (2011): In The Theory and Practice of Industrial Pharmacy; Lachman L, Lieberman HA, Kanig JL., Eds.; Philadelphia, USA: Varghese Publishing house, 293-345.

17. Du, J., Hoag, S.W. (2003): Characterization of excipient and tableting factors that influence folic acid dissolution, friability, and breaking strength of oil- and water soluble multivitamin with mineral tablets. Drug Development and Industrial Pharmacy, 29:1134-1147.

18. Pisek, R., Korselj, V., Vrecer, F. (2011): Comparison of direct rotor pelletization (fluid bed) and hign shear pelletization method for pellet production. Pharm and Biopharm, 53:327-333.

19. Allen, L.V., Popovich, N.G., Ansel, H.C. (2011): Ansel's pharmaceutical dosage forms and drug delivery systems. Edn. 8th, Lippincott Williams \& Wilkins, Philadelphia, 225-256. 
20. US Pharmacopeia National Formulary USP 23/NF 18. United States Pharmacopeial Convention. Inc., Rockville, MD, 1995.

21. Oishi, T.S., Nimmi, I., Islam, S.M.A. (2011): Comparative in vitro Bioequivalence Analysis of Some Generic Tablets of Atorvastatin, a BCS Class II Compound. Bangladesh Pharma. J., 14(1):61-66.

22. Lachman, L., Lieberman, H., Kanig, J. (1987): The theory and practice of industrial pharmacy. Edn, 3rd, Varghese publication house, 293-345.

23. Du, J., Hoag, S.W. (2003): Characterization of excipient and tableting factors that influence folic acid dissolution, friability, and breaking strength of oil- and water soluble multivitamin with mineral tablets. Drug Dev. and Indus. Pharm., 29:1134- 1147.

24. Waiver of in vivo bioavailability and bioequivalence studies for immediate-release solid oral dosage forms based on a biopharmaceutics classification system; guidance for industry; U.S. Department of Health and Human Services, Food and Drug Administration, Center for Drug Evaluation and Research (CDER), U.S. Government Printing Office: Washington, DC, 2000. 